\title{
Assessment of aflatoxin exposure using urine biomarker in pregnant and non-pregnant women in Yazd, Center of Iran
}

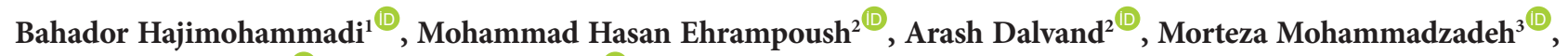 \\ Mansoureh Soltani ${ }^{+(\mathbb{D}}$, Soheyl Eskandari ${ }^{4,5 *}$ \\ ${ }^{1}$ Research Center for Food Hygiene and Safety, School of Public Health, Shahid Sadoughi University of Medical Sciences, Yazd, Iran \\ ${ }^{2}$ Environmental Science and Technology Research Center, Department of Environmental Health Engineering, School of Public Health, \\ Shahid Sadoughi University of Medical Sciences, Yazd, Iran \\ ${ }^{3}$ Department of Biostatistics, Faculty of Medical Science, Tarbiat Modares University, Tehran, Iran \\ ${ }^{4}$ Food and Drug Laboratory Research Center (FDLRC), Food and Drug Administration (IR-FDA), Ministry of Health and Medical \\ Education $(\mathrm{MOH}+\mathrm{ME})$, Tehran, Iran \\ ${ }^{5}$ Nutrition and Food Sciences Research Center, Tehran Medical Sciences, Islamic Azad University, Tehran, Iran
}

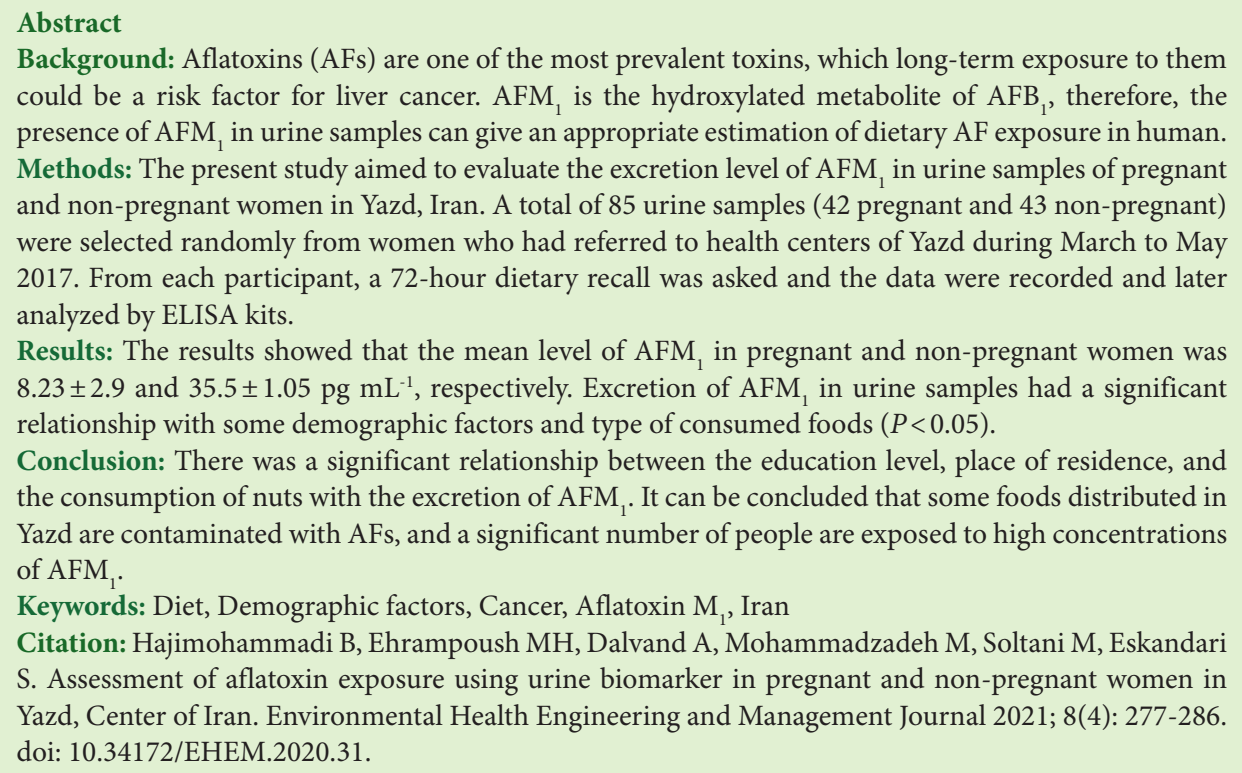
could be a risk factor for liver cancer. $\mathrm{AFM}_{1}$ is the hydroxylated metabolite of $\mathrm{AFB}_{1}$, therefore, the presence of $\mathrm{AFM}_{1}$ in urine samples can give an appropriate estimation of dietary $\mathrm{AF}$ exposure in human. Methods: The present study aimed to evaluate the excretion level of AFM in urine samples of pregnant and non-pregnant women in Yazd, Iran. A total of 85 urine samples (42 pregnant and 43 non-pregnant) were selected randomly from women who had referred to health centers of Yazd during March to May 2017. From each participant, a 72-hour dietary recall was asked and the data were recorded and later analyzed by ELISA kits.

Results: The results showed that the mean level of $\mathrm{AFM}_{1}$ in pregnant and non-pregnant women was $8.23 \pm 2.9$ and $35.5 \pm 1.05 \mathrm{pg} \mathrm{mL}^{-1}$, respectively. Excretion of $\mathrm{AFM}_{1}$ in urine samples had a significant relationship with some demographic factors and type of consumed foods $(P<0.05)$.

Conclusion: There was a significant relationship between the education level, place of residence, and the consumption of nuts with the excretion of $\mathrm{AFM}_{1}$. It can be concluded that some foods distributed in Yazd are contaminated with AFs, and a significant number of people are exposed to high concentrations of $\mathrm{AFM}_{1}$.

Keywords: Diet, Demographic factors, Cancer, Aflatoxin $\mathrm{M}_{1}$, Iran

Citation: Hajimohammadi B, Ehrampoush MH, Dalvand A, Mohammadzadeh M, Soltani M, Eskandari S. Assessment of aflatoxin exposure using urine biomarker in pregnant and non-pregnant women in Yazd, Center of Iran. Environmental Health Engineering and Management Journal 2021; 8(4): 277-286. doi: 10.34172/EHEM.2020.31.

Article History: Received: 15 March 2021 Accepted: 15 June 2021 ePublished: 12 November 2021

\section{Introduction}

Aflatoxins (AFs) are one of the most prevalent toxins, so that long-term exposure to them may lead to acute and chronic negative health effects and could be a risk factor for liver cancer. AFs are mainly produced by Aspergillus flavus, Aspergillus parasiticus, and Aspergillus nomius (1). These toxins are found in most of the crops, such as corn, peanuts, pistachio, soybean, coconut, rice, milk, dairy products, etc (2-4) and exist in multiple types including $B_{1}, B_{2}, G_{1}$, and $G_{2}(5)$. Aflatoxin $B_{1}\left(A F B_{1}\right)$ is highly toxic, mutagenic, teratogenic, and carcinogenic (6), which has been classified as Group 1 carcinogens by the International Agency for Research on Cancer (IARC) (7). For human, the extent of exposure to AFs depends on the level of consumption of polluted foods and the level of the toxin in different foods, such as dairy products (e.g. milk, cheese, and yogurt) (8), meat, meat products (9), rice (10), and eggs (11). New-born infants can be exposed to AFs whether in uterus or through breast feeding (12). Environmental exposure to AFs may cause liver cancer (13); furthermore, the existence of AFs in food may lead to both acute and chronic negative health effects (1) including immune-system suppression and liver cancer (14). Clinical symptoms of acute toxicity of AFs in human are as follows: vomiting, abdominal pain, pulmonary edema, liver necrosis (15), and sudden death (16). Besides, AFs can cause growth retardation and delayed development during infancy (17). Consumption 
of AF-contaminated food during pregnancy have adverse effects on infant growth, as it could be a teratogenic and jaundice-inducing toxin (18). Regulations for maximum contamination level of AFs in foods vary from country to country. According to the standards of the European Commission, the maximum allowable level of $\mathrm{AFB}_{1}$ and total AFs in crops can be 2 and $4 \mu \mathrm{g} / \mathrm{kg}$, respectively (19), while the Iranian National Standards Organization has assigned a maximum level of $5 \mathrm{ng} / \mathrm{g}$ for $\mathrm{AFB}_{1}$ and $15 \mathrm{ng} / \mathrm{g}$ for total AFs in crops (20).

$\mathrm{AFM}_{1}$ and $\mathrm{AFM}_{2}$, which are hydroxylated metabolites of $\mathrm{AFB}_{1}$ and $\mathrm{AFB}_{2}$, can be found in milk, milk products, urine, and blood (1). After ingestion, $\mathrm{AFB}_{1}$ is converted to its carcinogenic forms through metabolism by cytochrome P-450 enzymes in liver (1). Hence, the content of $\mathrm{AFM}_{1}$ in urine sample can be a clue to determine the extent of human exposure to $\mathrm{AF}$ (21), therefore, considering the complexity of investigating the exposure to AFs by determining their concentrations in consumed foods, some researchers have suggested to estimate it by quantitative assessment of metabolites in milk, blood, and urine (22).

Urinary biomarker has been used to estimate exposure to $\mathrm{AFB}_{1}$ in many studies. In a study by Lei et al, $\mathrm{AFM}_{1}$ was detected in $84 \%$ of the pregnant women (23). Ezekiel et al reported that the mean urinary $\mathrm{AFM}_{1}$ levels were significantly higher in the semi-urban population compared to the rural population (24). Ali et al also reported that the mean level of urinary $\mathrm{AFM}_{1}$ was higher in winter than in summer, and level of $\mathrm{AFM}_{1}$ in urine did not show significant associations with the participants' food consumption pattern (25). Although our previous study revealed the occurrence of $\mathrm{AFM}_{1}$ in urine of volunteers (26), there is not enough information about urinary concentration of $\mathrm{AFM}_{1}$ in Iranian women. Since AFs introduce mutagenic, carcinogenic, and teratogenic properties which cause anemia in women, particularly in pregnant women (27), and are risk factors for jaundice in infants (28), the main aim of this study was to evaluate the excretion level of $\mathrm{AFM}_{1}$ in urine samples of pregnant and non-pregnant women living in Yazd, Iran, as a biomarker of $\mathrm{AFB}_{1}$ exposure. Furthermore, the relationship between demographic factors and dietary intake with $\mathrm{AFM}_{1}$ excretion was investigated.

\section{Materials and Methods \\ Participant recruitment}

This study was conducted on resident population of Yazd, the capital of Yazd province located in the central part of Iran (29). A total of 85 urine samples (42 pregnant and 43 non-pregnant) were taken randomly from women who had referred to Yazd health centers (Azadshahr, Panbekaran, Maskan, and Safaieh) during March to May 2017. Before beginning the study, informed consent was obtained from participants to follow ethical regulations. Participants were selected among those who were eligible, such as pregnant women (20-year-old or older, in the last trimester of pregnancy) and non-pregnant women (20 to 50 years of age, not in lactation or menstrual period). Prior to urine sampling, each participant was asked about demographic factors (Table 1). Also, food frequency questionnaire (FFQ) was asked for intake of typical food items, such as rice, milk, dairy products, meat, nuts, traditional confection of Yazd, traditional Halva and Tahini (made from sesame and sugar) in 72 hours. The sterile plastic falcons were used to collect urine samples. The samples were transferred immediately to the laboratory and stored at $-20^{\circ} \mathrm{C}$.

\section{Determination of the AFM $M_{1}$ metabolite in urine}

ELISA kits were applied to measure the level of $\mathrm{AFM}_{1}$ in urine samples, and ELISA kits (6827 BN Arnhem, Euro Proxima Company, Arnhem, Netherlands) were used for detection of AFM. The features of ELISA kits are as following: LOD: $6 \mathrm{pg} / \mathrm{mL}$, LOQ: $9.42 \mathrm{pg} / \mathrm{mL}$, recovery: $95 \%$. The samples were prepared according to the manufacturer's instruction. All of the samples were centrifuged (Kubota Centrifuge Model 2810, Tokyo, Japan) at $2000 \times \mathrm{g}$ for 10 minutes at $4^{\circ} \mathrm{C}$. Then, they were diluted with sample dilution buffer with volume ratio of $1: 1$. Subsequently, $100 \mu \mathrm{L}$ of the $\mathrm{AFM}_{1}$ standard solution and test samples (diluted urine) and $10 \mu \mathrm{L}$ of standard $80 \mathrm{ng} / \mathrm{L}$ were added in duplicate to the wells of the plate, followed by 1 hour incubation at room temperature $\left(25^{\circ} \mathrm{C}\right)$ at dark. The solutions were removed from the microtiter plate and

Table 1. Socio-demographic characteristics of participants

\begin{tabular}{|c|c|c|}
\hline $\begin{array}{l}\text { Socio-demographic } \\
\text { Factors }\end{array}$ & $\begin{array}{l}\text { Pregnant } \\
\text { No. (\%) }\end{array}$ & $\begin{array}{c}\text { Non-pregnant } \\
\text { No. (\%) }\end{array}$ \\
\hline \multicolumn{3}{|l|}{ Age (year) } \\
\hline $20-30$ & $40(95.2)$ & $14(32.6)$ \\
\hline $30-40$ & $2(4.8)$ & $13(30.2)$ \\
\hline $40-50$ & $0(0)$ & $16(37.2)$ \\
\hline \multicolumn{3}{|l|}{ Education level } \\
\hline Primary & $8(19)$ & $26(60.5)$ \\
\hline Secondary & $22(52.4)$ & $10(23.3)$ \\
\hline University & $12(28.6)$ & $7(16.3)$ \\
\hline \multicolumn{3}{|l|}{ Occupational status } \\
\hline Employed & $10(23.8)$ & $11(25.6)$ \\
\hline Housewife & $32(76.2)$ & $32(74.4)$ \\
\hline \multicolumn{3}{|l|}{ Monthly income } \\
\hline$<195 \$$ & $8(19)$ & $12(27.9)$ \\
\hline $195-387 \$$ & $22(52.4)$ & $17(39.5)$ \\
\hline$>387 \$$ & $12(28.6)$ & $14(32.6)$ \\
\hline \multicolumn{3}{|l|}{ Geographic region } \\
\hline Azadshahr & $10(23.8)$ & $10(23.3)$ \\
\hline Panbekaran & $10(23.8)$ & $10(23.3)$ \\
\hline Maskan & $11(26.2)$ & $11(25.6)$ \\
\hline Safaieh & $11(26.2)$ & $12(27.9)$ \\
\hline
\end{tabular}


washed three times with rinsing buffer. In the next step, $100 \mu \mathrm{L}$ of conjugate (Aflatoxin M-HRPO) was added to each well of the plate, except zero standard maximal wells, and incubated for $30 \mathrm{~min}$ at $25^{\circ} \mathrm{C}$ at dark. The solutions were again removed from the microtiter plate and washed three times with rinsing buffer. Thereafter, $100 \mu \mathrm{l}$ of enzyme substrate was added to each well and incubated for 30 minutes at room temperature $\left(20-25^{\circ} \mathrm{C}\right)$. The reaction was stopped by adding $100 \mu \mathrm{L}$ stop solution to each well, and absorbance of each well was read at $450 \mathrm{~nm}$ via a microplate reader (ELX $800 \mathrm{UV}$, Bio-Tek Instruments, Inc. optical density of solutions in 6-, 12-, 24-, 48 or 96-well microplates in the wavelength range from $400 \mathrm{~nm}$ to $750 \mathrm{~nm}$ ). A standard curve was drawn by plotting absorbance values against $\mathrm{AFM}_{1}$ concentrations. The absorption intensity was inversely proportional to $\mathrm{AFM}_{1}$ concentration in urine samples.

\section{Statistical analysis}

The data were analyzed using SPSS version 20 (IBM SPSS Inc., Chicago, IL). Mann-Whitney U test was used to compare the two groups and determine the relationship between food intake and the concentration of $\mathrm{AFM}_{1}$ in urine samples. Kruskal-Wallis one-way ANOVA test was used to determine the relationship between types of consumed rice (Native, Imported, or Both), place of residence (Azadshahr, Panbekaran, Maskan, Safaieh), and concentration of $\mathrm{AFM}_{1}$. Statistically significant level was considered at $P<0.05$.

\section{Results}

Forty-two pregnant and forty-three non-pregnant respondents, with a mean age of $31.4 \pm 9.5$ years $(25.2 \pm 3.4$ years for pregnant women and $37.4 \pm 9.6$ years for nonpregnant women), participated in this study. The results showed that from a total of 85 participants, 80 people (94.1\%) had excreted $\mathrm{AFM}_{1}$ in the range of $0.4-67.8 \mathrm{pg}$ $\mathrm{mL}^{-1}$. Excretion of $\mathrm{AFM}_{1}$ in urine samples had a significant relationship $(P<0.05)$ with some demographic factors, such as age, education level, income level, and place of residence, as well as consumption of some types of foods including rice, nuts, traditional confection of Yazd, Tahini and traditional Halva. However, there was no significant relationship between the excretion of $\mathrm{AFM}_{1}$ and occupational status as well as consumption of milk, dairy products, and meat (Tables 2 and 3). In the non-pregnant group, all patients (100\%) had excreted $\mathrm{AFM}_{1}$, and a significant relationship was observed between some demographic factors (i.e., age, body mass index [BMI], education level, income level, and place of residence) and food consumption (i.e., rice, nuts, traditional confection Yazd, Tahini and traditional Halva) with the excretion of $\mathrm{AFM}_{1}$. AFM 1 was found in $90.47 \%$ of urine samples of pregnant women. There was a significant relationship between the education level, place of residence, and the consumption of nuts with the excretion of $\mathrm{AFM}_{1}$ (Tables 4 and 5).

\section{Discussion}

The presence of $\mathrm{AFM}_{1}$ in urine samples can give an appropriate estimation of dietary AF exposure in human (21). The present results showed that $\mathrm{AFM}_{1}$ level in Yazd population was higher than that in some countries, such as Brazil, Egypt, and Guinea (22,30,31). Urinary tests have shown that high percentage of the population of several countries in Asia and Africa are exposed to AFs. For instance, Sabran et al (21) found that the mean concentration of $\mathrm{AFM}_{1}$ in urine samples of Malaysian population $(\mathrm{n}=22)$ was $42.1 \mathrm{pg} \mathrm{mL}^{-1}$. The range of urinary $\mathrm{AFM}_{1}$ detected by Ali et al was 31-348 $\mathrm{ng} \mathrm{mL}^{-1}$ (32). De Cássia Romero et al evaluated urinary excretion of $\mathrm{AFM}_{1}$ in Brazilians, and reported that $65 \%$ of them showed contamination with a mean concentration of $1.8 \mathrm{pg} \mathrm{mL}^{-1}$ (22). Polychronaki et al detected $\mathrm{AFM}_{1}$ in urine samples of $38 \%$ of Egyptians and $86 \%$ of Guineans (30). Ali et al. reported that $\mathrm{AFM}_{1}$ was detected in more than $40 \%$ of all urine samples of Bangladeshi population at a range of $1.7-104 \mathrm{pg} / \mathrm{mL}$ in summer and at a range of $1.8-190 \mathrm{pg} /$ $\mathrm{mL}$ in winter season (25). Schwartzbord et al reported a significant correlation between the dietary intake of $\mathrm{AFB}_{1}$ and the $\mathrm{AFM}_{1}$ concentration in urine samples (33). In the present study, the excretion of $\mathrm{AFM}_{1}$ was observed in about $94 \%$ of women in Yazd, and the range of excreted $\mathrm{AFM}_{1}$ was $0.4-67.8 \mathrm{pg} \mathrm{mL}^{-1}$ with a mean concentration of $22.03 \pm 1.9 \mathrm{pg} \mathrm{mL}^{-1}$. There was a significant relationship between the excretion of $\mathrm{AFM}_{1}$ and age, as the excretion of $\mathrm{AFM}_{1}$ increased by increasing age. Hence, the highest levels of $\mathrm{AFM}_{1}$ excretion were observed in age group of older than 30 years. On the other hand, there was no significant association between age and excretion of AFM in pregnant women; nonetheless, excretion of $\mathrm{AFM}_{1}$ was observed in some of older participants (31-40 years) of this group. Lei et al reported a significant relationship between the excretion level of $\mathrm{AFM}_{1}$ and age, as they noticed that the concentration of $\mathrm{AFM}_{1}$ was conspicuously high in the age group of older than 28 years (23). As well, the results of the study done by Ali et al revealed that the highest mean $\mathrm{AFM}_{1}$ level $\left(101 \pm 71 \mathrm{pg} \mathrm{mL}^{-1}\right)$ was observed in the age group of 50-60 years (25). Epidemiological studies have shown that there is a direct relationship between intake of $\mathrm{AFB}_{1}$ and liver cancer, so that over $90 \%$ of liver cancer cases are diagnosed after the age of 45 years, when the excretion level of $\mathrm{AFM}_{1}$ is high (34).

To avoid the effect of false weight gained during pregnancy, this parameter was assessed by BMI only in the non-pregnant group. According to the results, there was a significant relationship between BMI and the excretion of $\mathrm{AFM}_{1}$, as the highest levels of $\mathrm{AFM}_{1}$ excretion were observed in women with BMI $>30$. Polychronaki et al observed a significant association between the excretion of $\mathrm{AFM}_{1}$ and $\mathrm{BMI}$, as the concentration of $\mathrm{AFM}_{1}$ was very high in obese people (BMI >30) (35).

In various studies, different relationships between the excretion of $\mathrm{AFM}_{1}$ and geographical location have been 
Table 2. Correlation between AFM1 excretion in urine samples and socio-demographic factors

\begin{tabular}{|c|c|c|c|c|}
\hline $\begin{array}{l}\text { Socio-demographic } \\
\text { Factors }\end{array}$ & Sample Tested (N) & Positive Samples N (\%) & Min-max $\left(p g \mathrm{~mL}^{-1}\right)$ & Mean $\pm S D\left(p g ~ m L^{-1}\right)$ \\
\hline \multicolumn{5}{|l|}{ Pregnancy status } \\
\hline Pregnant & $42^{a *}$ & $37(88.1)$ & $0-23.8$ & $8.23 \pm 2.9$ \\
\hline Non-pregnant & $43^{b}$ & $43(100)$ & $13.6-67.8$ & $35.5 \pm 1.05$ \\
\hline \multicolumn{5}{|l|}{ Age (year) } \\
\hline $20-30$ & $54^{a}$ & $49(90.7)$ & $0-54$ & $14.4 \pm 1.2$ \\
\hline $30-40$ & $15^{\mathrm{b}}$ & $15(100)$ & $0.4-54.6$ & $29.9 \pm 1.8$ \\
\hline $40-50$ & $16^{c}$ & $16(100)$ & $13.6-67.8$ & $37.7 \pm 1.6$ \\
\hline \multicolumn{5}{|l|}{$\operatorname{BMI}\left(\mathrm{kg} / \mathrm{m}^{2}\right)^{\star *}$} \\
\hline$<24.9$ & $12^{\mathrm{a}}$ & $12(100)$ & $16.8-54$ & $28.63 \pm 1.3$ \\
\hline $25-29.9$ & $20^{b}$ & $20(100)$ & $13.6-54.6$ & $33.35 \pm 3.2$ \\
\hline$>30$ & $11^{\mathrm{c}}$ & $11(100)$ & $23.8-67.8$ & $46.99 \pm 1.5$ \\
\hline \multicolumn{5}{|l|}{ Education level } \\
\hline Primary & $34^{\mathrm{a}}$ & $34(100)$ & $1.6-60.2$ & $31.3 \pm 1.6$ \\
\hline Secondary & $32^{\mathrm{b}}$ & $29(100)$ & $0-53$ & $14.2 \pm 1.3$ \\
\hline University & $19^{b}$ & $17(100)$ & $0-67.8$ & $18.4 \pm 1.8$ \\
\hline \multicolumn{5}{|l|}{ Occupational status } \\
\hline Employed & $21^{\mathrm{a}}$ & $19(90.5)$ & $0-67.8$ & $20.1 \pm 1.9$ \\
\hline Housewife & $64^{\mathrm{a}}$ & $61(95.3)$ & $0-60.2$ & $22.6 \pm 1.6$ \\
\hline \multicolumn{5}{|l|}{ Monthly income } \\
\hline$<195 \$$ & $20^{\mathrm{a}}$ & $20(100)$ & $1.8-60.2$ & $31.9 \pm 1.9$ \\
\hline $195-387 \$$ & $39^{b}$ & 35 (89.7) & $0-55.4$ & $17.7 \pm 1.4$ \\
\hline$>387 \$$ & $26^{b}$ & $25(96.2)$ & $0-67.8$ & $20.8 \pm 1.6$ \\
\hline \multicolumn{5}{|l|}{ Geographic region } \\
\hline Azadshahr & $20^{\mathrm{a}}$ & $20(100)$ & $1.8-59.4$ & $24.7 \pm 1.7$ \\
\hline Panbekaran & $20^{\mathrm{b}}$ & $20(100)$ & $7.2-67.8$ & $32.7 \pm 1.9$ \\
\hline Maskan & $22^{\mathrm{ac}}$ & $19(86.4)$ & $0-55.4$ & $14.6 \pm 1.1$ \\
\hline Safaieh & $23^{c}$ & $21(91.3)$ & $0-47.8$ & $17.4-1.4$ \\
\hline
\end{tabular}

${ }^{*}$ In each section, different letters on the same column indicate that there is a statistical significant difference between each factor $(P<0.05)$.

${ }^{* *}$ Because of false weight gain during pregnancy, BMI was calculated only in non-pregnant women.

reported. Lei et al found no significant relationship between the excretion of $\mathrm{AFM}_{1}$ and region of residence (23), while Polychronaki et al observed a significant correlation between the excretion of $\mathrm{AFM}_{1}$ and geographical location in children of Egypt and Guinea (30). In the present study, a significant relationship between the excretion of AFM and geographic region was found. The average excretion of $\mathrm{AFM}_{1}$ in Panbekaran locale was higher than that of other three regions (Azadshahr, Maskan, and Safaieh). Based on the answers to the question about the way of procuring food, most residents of Panbekaran bought their foods in bulk and non-packaging form from traditional shops. Undesirable ventilation and lack of hygiene in the traditional shops provide the conditions for fungal growth and AF production on food products. Approximately, $50 \%$ of Panbekaran locals had incomes less than 195 dollars per month, and in comparison with Azadshahr, Maskan, and Safaieh regions, the highest rate of excretion of $\mathrm{AFM}_{1}$, in each income level, belonged to Panbekaran locals. Research done in Malaysia showed that the rate of excretion of $\mathrm{AFM}_{1}$ was higher in participants with low education levels $(P=0.4)$. In the present study, the rate of excretion of $\mathrm{AFM}_{1}$ was also higher in people with low education levels $(P<0.001)$, where $40 \%$ of participants had primary education, $37.6 \%$ secondary education, and $22.4 \%$ university education. The mean level of $\mathrm{AFM}_{1}$ excretion $\left(41.2 \mathrm{pg} \mathrm{mL}^{-1}\right.$ ) in participants with primary education was more than that in those with secondary or university education. Therefore, it was found that the excretion of AF had a significant relationship with the level of education in both pregnant and non-pregnant groups. In both groups, the highest level of $\mathrm{AFM}_{1}$ excretion was observed in participants with primary education. On the other hand, there was no significant association between occupational status and excretion of $\mathrm{AFM}_{1}$. The level of $\mathrm{AFM}_{1}$ excretion in housewives was $11 \%$ more than that in 
Table 3. Correlation between AFM1 excretion in urine samples and consumption of foods in recent 72 hours

\begin{tabular}{|c|c|c|c|c|c|}
\hline $\begin{array}{l}\text { Foods Consumed in } \\
\text { Recent } 72 \text { Hours }\end{array}$ & $\begin{array}{l}\text { Sample } \\
\qquad N\end{array}$ & $\begin{array}{c}\text { Positive Samples } \\
\text { N (\%) }\end{array}$ & $\begin{array}{l}\text { Min-max } \\
\left(\mathrm{pg} \mathrm{mL^{-1 }}\right)\end{array}$ & $\begin{array}{l}\text { Mean } \pm \text { SD } \\
\left(p g \mathrm{~mL}^{-1}\right)\end{array}$ & $P$ value \\
\hline \multicolumn{6}{|l|}{ Milk } \\
\hline Yes & 73 & $69(94.5)$ & $0-67.8$ & $23.1 \pm 1.8$ & \multirow{2}{*}{0.1} \\
\hline No & 12 & $11(91.6)$ & $0-39.8$ & $15.9 \pm 1.1$ & \\
\hline \multicolumn{6}{|l|}{ Meat } \\
\hline Yes & 71 & $67(94.3)$ & $0-67.8$ & $21.9 \pm 1.9$ & \multirow{2}{*}{0.9} \\
\hline No & 14 & $13(92.8)$ & $0-54.6$ & $22.2 \pm 1.5$ & \\
\hline \multicolumn{6}{|l|}{ Traditional confection } \\
\hline Yes & 29 & $29(100)$ & $1-67.8$ & $29.6 \pm 3.4$ & \multirow{2}{*}{0.002} \\
\hline No & 56 & $51(91.1)$ & $0-60.2$ & $18.1 \pm 2.1$ & \\
\hline \multicolumn{6}{|l|}{ Nuts } \\
\hline Yes & 53 & $49(92.5)$ & $0-67.8$ & $29.8 \pm 3.4$ & \multirow{2}{*}{0.02} \\
\hline No & 32 & $31(95.5)$ & $0-59.2$ & $17.7 \pm 2.1$ & \\
\hline \multicolumn{6}{|l|}{ Traditional Halva } \\
\hline Yes & 17 & $17(100)$ & $1.2-67.8$ & $35.7 \pm 5.4$ & \multirow{2}{*}{0.001} \\
\hline No & 67 & $64(93.3)$ & $0-59.2$ & $19.1 \pm 1.6$ & \\
\hline \multicolumn{6}{|l|}{ Rice } \\
\hline \multicolumn{6}{|l|}{ Native } \\
\hline Yes & 23 & $19(82.6)$ & $0-37$ & $15.8 \pm 1.9$ & \multirow{2}{*}{0.4} \\
\hline No & 8 & $8(100)$ & $1-26.1$ & $12.5 \pm 1.1$ & \\
\hline \multicolumn{6}{|l|}{ Imported } \\
\hline Yes & 29 & $29(100)$ & $3.2-60.2$ & $28.6 \pm 3.8$ & \multirow{2}{*}{0.03} \\
\hline No & 5 & $5(100)$ & $5.4-32$ & $13.4 \pm 1.1$ & \\
\hline \multicolumn{6}{|l|}{ Both } \\
\hline Yes & 15 & $14(93.3)$ & $6.4-67.8$ & $29.1 \pm 4.7$ & \multirow{2}{*}{0.1} \\
\hline No & 5 & $5(100)$ & $0-47.8$ & $14.9 \pm 2.8$ & \\
\hline
\end{tabular}

employed women. According to a similar study conducted by Mason et al, there was no relationship between the demographic factors and excretion of $\mathrm{AFM}_{1}$, while a significant difference between the excretion of $\mathrm{AFM}_{1}$ and consumption of nuts as well as traditional confection was observed (26).

The correlation between the level of $\mathrm{AFM}_{1}$ in urine samples and the type of consumed food has also been investigated. According to a study done by Jager et al, a significant relationship $(P<0.05)$ was found between consumption of milk, dairy products, corn, white hominy, and bean with excretion of $\mathrm{AFM}_{1}$ (31). In Haitian population, an association between the consumption of maize, peanut products, and milk with the excretion of $\mathrm{AFM}_{1}$ has been reported, wherein the level of $\mathrm{AFM}_{1}$ in urine was found to be significantly associated with peanut consumption $(P<0.05)(36)$. The nuts, as rich sources of protein, fatty acids, fiber, and vitamins (37), are recommended to be taken during pregnancy $(38,39)$. Based on the results of this study, there was a significant association between $\mathrm{AFM}_{1}$ excretion and consumption of nuts. In several studies, it has been reported that some edible nuts in Iran are contaminated by $\mathrm{AFB}_{1}(4,40)$. Rice is one of the most important foods widely used around the world including Iran, and it is used not only as a food, but also as an ingredient for a variety of foods, such as noodles, snacks, pasta, and chips (41). After bread, rice is the staple food in Iran. The average consumption of bread and rice in Iran is 107-286 grams per person per day (42). If it is assumed that the average total AF in rice is $9.56 \mu \mathrm{g} \mathrm{kg}^{-1}$, and $30 \%$ of it is eliminated in cooking process, each person receives 11.9-31.8 $\mathrm{ng} \mathrm{kg}^{-1}$ b.w of AF by daily consumption of rice (43). More than $50 \%$ of the rice consumed in Iran, especially imported rice, is contaminated with AFs $(10,44)$. The results of the present research revealed that there was a significant association between the rice consumption $(P=0.01)$ and, type of consumed rice $(P=0.02)$ with the excretion of $\mathrm{AFM}_{1}$. The excretion of $\mathrm{AFM}_{1}$ in people who had consumed rice was higher than those who had not. The average excretion of $\mathrm{AFM}_{1}$ in the people who had consumed imported rice was approximately 2-fold higher than those who had not $(P=0.03)$, while the average excretion of $\mathrm{AFM}_{1}$ in the people who had consumed Iranian rice was merely 
Table 4. Occurrence of AFM1 in urine samples of pregnant and non-Pregnant women according to the socio-demographic factors

\begin{tabular}{|c|c|c|c|c|c|c|}
\hline \multirow{2}{*}{$\begin{array}{l}\text { Socio-demographic } \\
\text { Factors }\end{array}$} & \multicolumn{3}{|c|}{ Pregnant } & \multicolumn{3}{|c|}{ Non-pregnant } \\
\hline & $\begin{array}{l}\text { Min-Max } \\
\left(\text { pg mL-1) }^{-1}\right.\end{array}$ & $\begin{array}{l}\text { Mean } \pm \text { SD Error } \\
\left(\mathrm{pg} \mathrm{mL}^{-1}\right)\end{array}$ & Correlation & $\begin{array}{l}\text { Min-Max } \\
\left(\mathrm{pg} \mathrm{mL}^{-1}\right)\end{array}$ & $\begin{array}{l}\text { Mean } \pm \text { SD Error } \\
\quad\left(\mathrm{pg} \mathrm{mL}^{-1}\right)\end{array}$ & Correlation \\
\hline \multicolumn{7}{|l|}{ Age (year) } \\
\hline $20-30$ & $0-23.8$ & $8.07 \pm 1.08$ & $a^{*}$ & $13.6-39.8$ & $26.5 \pm 2.1$ & a \\
\hline $30-40$ & $5.4-17.4$ & $11.4 \pm 6$ & a & $16.8-54.6$ & $33.8 \pm 4.2$ & $a b$ \\
\hline $40-50$ & - & - & - & $18.2-67.8$ & $44.1 \pm 3.2$ & $b$ \\
\hline \multicolumn{7}{|l|}{$\mathrm{BMI}^{* *}\left(\mathrm{~kg} / \mathrm{m}^{2}\right)$} \\
\hline$<24.9$ & - & - & - & $13.6-35.2$ & $25.7 \pm 1.8$ & a \\
\hline $25-29.9$ & - & - & - & $16.8-60.2$ & $37.18 \pm 3.2$ & $b$ \\
\hline$>30$ & - & - & - & $16.8-67.8$ & $43.6 \pm 4.1$ & $b$ \\
\hline \multicolumn{7}{|l|}{ Education level } \\
\hline Primary & $1.8-23.8$ & $15.35 \pm 2.8$ & a & $13.6-67.8$ & $41.2 \pm 2.8$ & a \\
\hline Secondary & $0-19$ & $8.4 \pm 1.3$ & $b$ & $17.8-59.2$ & $30.5 \pm 3.3$ & $\mathrm{~b}$ \\
\hline University & $0-14.6$ & $4.1 \pm 1.2$ & $b$ & $16.8-33.2$ & $25.5 \pm 3.1$ & $b$ \\
\hline \multicolumn{7}{|l|}{ Occupational status } \\
\hline Employed & $0-19$ & $6.1 \pm 2.1$ & a & $16.8-67.8$ & $35.37 \pm 4.2$ & a \\
\hline Housewife & $0-23.8$ & $8.9 \pm 1.2$ & a & $13.6-60.2$ & $35.5 \pm 2.4$ & a \\
\hline \multicolumn{7}{|l|}{ Monthly income } \\
\hline$<195 \$$ & $1.8-17.4$ & $10.7 \pm 1.6$ & a & $24.2-60.2$ & $45.4 \pm 3.5$ & a \\
\hline $195-387 \$$ & $0-19$ & $7.7 \pm 1.52$ & a & $13.6-55.4$ & $30.1 \pm 2.8$ & $b$ \\
\hline$>387 \$$ & $0-23.8$ & $7.2 \pm 2.1$ & a & $16.8-67.8$ & $33.6 \pm 3.5$ & $\mathrm{~b}$ \\
\hline \multicolumn{7}{|l|}{ Geographic region } \\
\hline Azadshahr & $0.4-17.4$ & $8.06 \pm 1.8$ & a & $27.8-59.4$ & $39.7 \pm 3.1$ & abd \\
\hline Panbekaran & $7.2-23.8$ & $16.02 \pm 1.6$ & $\mathrm{~b}$ & $30.8-67.8$ & $49.5 \pm 3.8$ & bcd \\
\hline Maskan & $0.3-17.4$ & $5.3 \pm 1.8$ & a & $13.6-55.4$ & $25.54 \pm 3.5$ & $\mathrm{~cd}$ \\
\hline Safaieh & $0-11.5$ & $4.2 \pm 1.1$ & a & $16.8-47.8$ & $29.5 \pm 2.5$ & acd \\
\hline
\end{tabular}

${ }^{*}$ In each section, different letters on the same column indicate that there is a correlation between factors.

${ }^{* *}$ Because of false weight gain during pregnancy, BMI was calculated only in non-pregnant women.

about $26 \%$ higher than those who had not $(P>0.05)$. The results of a cohort study done in Bangladesh indicated that the urinary $\mathrm{AFM}_{1}$ level had a direct correlation with the consumption of rice $(P=0.09)(32)$. Ferri et al observed a significant association between the excretion of $\mathrm{AFM}_{1}$ and consumption of rice products (45). Interestingly, the present study not only showed no significant association between the meat consumption and the excretion of $\mathrm{AFM}_{1}$, but also showed that the people who had consumed meat had excreted lower AFM. This finding is probably due to the existence of proteins and vitamins in meat. The previous studies on animals have shown that the diets which are rich of vitamins and proteins can reduce the toxic effects of AF (1). De Cássia Romero et al reported no significant relationship between the consumption of milk or milk-based products and the urinary excretion of $\mathrm{AFM}_{1}$. The findings of the present study also showed no significant relationship between the excretion of AFM and the consumption of milk and dairy products.

It was observed that the urinary excretion level of AFM $_{1}$ in participants who had consumed traditional confection of Yazd was significantly higher than those who had not. The main ingredients of Yazd traditional confections are sugar, wheat flour, walnut, pistachio, and almond. Due to the economic benefits, some Iranian confectioners prefer to use low-price nuts which usually have low quality and are more polluted with $\mathrm{AFB}_{1}$ (46). In both groups of this study, approximately $34 \%$ of participants had consumed traditional confection, and the AF level in their urine samples was in the range of 1.2-67.8 $\mathrm{pg} \mathrm{mL}^{-1}$. Sesame is the main constituent of traditional Halva and Tahini. In some studies, it has been reported that $\mathrm{AFB}_{1}$, which is the most toxic form of AFs and a risk factor for human health, exists in sesame seeds (47). The results of the present study revealed that the people who had consumed traditional Halva and Tahini excreted higher levels of AF than those who had not. Besides, it was indicated that the mean level of $\mathrm{AFM}_{1}$ excretion in non-pregnant women was 4.3-fold higher $(P<0.001)$ than that in pregnant women.

The obtained results exhibited that overweight, age, and the consumption of traditional confections Halva and Tahini could be the most influential factors in the high 


\begin{tabular}{|c|c|c|c|c|c|c|}
\hline \multirow{2}{*}{$\begin{array}{l}\text { Foods Consumed in Recent } \\
72 \text { Hours }\end{array}$} & \multicolumn{3}{|c|}{ Pregnant } & \multicolumn{3}{|c|}{ Non-pregnant } \\
\hline & $\mathbf{N}(\%)$ & $\begin{array}{c}\text { Mean } \pm \text { SD Error (pg } \\
\mathrm{mL}^{-1} \text { ) }\end{array}$ & $P$ value & N (\%) & $\begin{array}{c}\text { Mean } \pm \text { SD Error (pg } \\
\left.\mathrm{mL}^{-1}\right)\end{array}$ & $P$ value \\
\hline \multicolumn{7}{|l|}{ Milk } \\
\hline Yes & $36(85.7)$ & $8.4 \pm 1.1$ & \multirow{2}{*}{0.4} & $31(72.1)$ & $37.6 \pm 2.5$ & \multirow{2}{*}{0.7} \\
\hline No & $6(14.3)$ & $6.9 \pm 1.7$ & & $12(27.9)$ & $30.1 \pm 3.1$ & \\
\hline \multicolumn{7}{|l|}{ Meat } \\
\hline Yes & $35(83.3)$ & $7.7 \pm 1.2$ & \multirow{2}{*}{0.2} & $32(74.4)$ & $35.8 \pm 2.5$ & \multirow{2}{*}{0.9} \\
\hline No & $7(16.7)$ & $10.5 \pm 2.4$ & & $11(25.6)$ & $34.6 \pm 3.7$ & \\
\hline \multicolumn{7}{|l|}{ Traditional confection } \\
\hline Yes & $14(33.3)$ & $10.3 \pm 2.1$ & \multirow{2}{*}{0.1} & $16(37.2)$ & $41.5 \pm 3.7$ & \multirow{2}{*}{0.03} \\
\hline No & $28(66.7)$ & $7.1 \pm 1.2$ & & $27(62.8)$ & $31.9 \pm 2.2$ & \\
\hline \multicolumn{7}{|l|}{ Nuts } \\
\hline Yes & $24(57.1)$ & $11.1 \pm 1.5$ & \multirow{2}{*}{0.007} & $15(34.9)$ & $42.4 \pm 4.1$ & \multirow{2}{*}{0.01} \\
\hline No & $11(42.9)$ & $6.1 \pm 1.3$ & & $28(65.1)$ & $31.8 \pm 2.2$ & \\
\hline \multicolumn{7}{|l|}{ Traditional Halva and Tahini } \\
\hline Yes & $8(19.1)$ & $10.3 \pm 2.6$ & \multirow{2}{*}{0.3} & $12(20.9)$ & $43.7 \pm 3.2$ & \multirow{2}{*}{0.04} \\
\hline No & $34(80.9)$ & $7.7 \pm 1.1$ & & $31(79.1)$ & $32.3 \pm 2.4$ & \\
\hline \multicolumn{7}{|l|}{ Rice } \\
\hline \multicolumn{7}{|l|}{ Native } \\
\hline Yes & $14(78.2)$ & $6.9 \pm 1.4$ & \multirow{2}{*}{0.7} & $9(64.3)$ & $30.2 \pm 6.3$ & \multirow{2}{*}{0.8} \\
\hline No & $4(21.8)$ & $9.7 \pm 4.3$ & & $5(35.7)$ & $28.6 \pm 2.4$ & \\
\hline \multicolumn{7}{|l|}{ Imported } \\
\hline Yes & $6(60)$ & $11.3 \pm 2.3$ & \multirow[b]{2}{*}{0.2} & $14(73.7)$ & $47.8 \pm 3.3$ & \multirow{2}{*}{0.009} \\
\hline No & $4(40)$ & $5.5 \pm 3.1$ & & $5(26.3)$ & $20.24 \pm 3.2$ & \\
\hline \multicolumn{7}{|l|}{ Both } \\
\hline Yes & $6(66.7)$ & $8.5 \pm 4.1$ & \multirow{2}{*}{0.5} & $7(70)$ & $35.7 \pm 3.8$ & \multirow{2}{*}{0.6} \\
\hline No & $3(33.3)$ & $6.4 \pm 3.4$ & & $3(30)$ & $33 \pm 1.7$ & \\
\hline
\end{tabular}

excretion of $\mathrm{AFM}_{1}$ in urine. In addition to the possibility of their contamination with AF, the consumption of traditional confections Halva and Tahini can cause obesity because of their high oil and sugar content. Obesity is associated with increased risk of liver disease (48). As previously reported, all these factors (i.e., old age, obesity, and intake of $\mathrm{AF}$ ) are the risk factors for liver cancer $(34,49,50)$ and there is a significant correlation between excretion of $\mathrm{AFM}_{1}$ in urine and liver cancer (51). Thus, these findings could be considered as a risk assessment.

In the present study, the heterogeneity of food contamination resulted from pregnant women's tendency to consume the best food with the best quality during pregnancy, the differences in type of consumed foods, and the differences in age were the impressive factors which could affect the excretion of $\mathrm{AFM}_{1}$ in the two groups (pregnant and non-pregnant). As shown in the results, the excretion rate of $\mathrm{AFM}_{1}$ increased with increasing age (the mean age of the pregnant and non-pregnant women was 25 and 37 years, respectively). The lower excretion of $\mathrm{AFM}_{1}$ in pregnant women, as compared to non-pregnant ones, can be attributed to the transmittance of AF to the fetus through the umbilical cord $(52,53)$ which causes a decrease in the excretion of $\mathrm{AFM}_{1}$ in pregnant women. Moreover, the consumption of different types of vitamins $(1,54)$ such as vitamins A, B, C, and D, and supplements during pregnancy may result in a decrease in the excretion of $\mathrm{AFM}_{1}$ in pregnant women. Nonetheless, these findings need to be further investigated.

Based on the obtained results in the present research, it seems that some of the foods used in Yazd are highly contaminated with AFs, and many people of Yazd are exposed to high concentrations of AF and its associated health risks. This health problem needs the attention of government and health departments, as the government can play a key role in reducing the exposure to $A_{F}$. Furthermore, health officials should warn the public (especially vulnerable groups, such as children, elderly, and old pregnant women) about the consumption of AFcontaminated foods and the harmful effects associated with it. Also, detecting and introducing the sources of AF can help consumers to avoid consuming foods which are most likely to be contaminated. As complete elimination of AF from the diet is impossible, the toxic effects of AF 
can be reduced by taking vitamins and probiotic products. Because of the dire consequences of exposure to AF for humans and animals, it is of great importance to reduce exposure to AF as much as possible. AF exposure can be prevented or decreased by improving and enforcing safety regulations, changing crop storage practices, detoxification and modifying the dominant diet. For example, it has been shown that by increasing the consumption of probiotic products, the AF exposure can be reduced (55). Certain food preparation techniques, such as fermentation, may reduce the intestinal absorption of AFs (56).

\section{Conclusion}

This research aimed to determine the AF exposure of pregnant and non-pregnant women in Yazd, Iran, using urinary biomarkers. The mean level of $\mathrm{AFM}_{1}$ in pregnant and non-pregnant women was $8.23 \pm 2.9$ and $35.5 \pm 1.05 \mathrm{pg}$ $\mathrm{mL}^{-1}$, respectively. The results revealed that the excretion of $\mathrm{AFM}_{1}$ in the urine samples had a significant relationship with some demographic factors and type of consumed foods. Besides, it was shown that some consumed foods in Yazd were highly contaminated with AFs. Hence, it can be concluded that many people are exposed to high concentrations of AF and its related hazards; so, as a part of cancer control program, some preventive strategies need to be suggested to reduce AF intake through food.

\section{Acknowledgments}

This article is a part of an MSc thesis that supported by Faculty of Health, Shahid Sadoughi University of Medical Sciences, Yazd, Iran. The authors would like to express their gratitude to Prof. A. Mohammadipour for editing the manuscript.

\section{Conflict of interests}

The authors declare that there is no conflict of interests.

\section{Ethical issues}

The authors certify that all data collected during the study are as presented in the manuscript and no data from the study has been or will be published elsewhere separately.

\section{Authors' contributions}

All authors participated in the problem suggestion, experiments design, data collection, and manuscript approval.

\section{References}

1. Benkerroum N. Chronic and acute toxicities of aflatoxins: Mechanisms of action. Int J Environ Res Public Health 2020; 17(2): 423. doi: 10.3390/ijerph17020423.

2. Herzallah SM. Determination of aflatoxins in eggs, milk, meat and meat products using HPLC fluorescent and UV detectors. Food Chem 2009; 114(3): 1141-6. doi: org/10.1016/j.foodchem.2008.10.077.

3. Rahimi E, Karim G, Shakerian A. Occurrence of aflatoxin M1 in traditional cheese consumed in Esfahan, Iran. World Mycotoxin J 2009; 2(1): 91-4. doi: 10.3920/WMJ2008.1082.
4. Cheraghali AM, Yazdanpanah H, Doraki N, Abouhossain G, Hassibi M, Ali-abadi S, et al. Incidence of aflatoxins in Iran pistachio nuts. Food Chem Toxicol 2007; 45(5): 812-6. doi: 10.1016/j.fct.2006.10.026.

5. Kumi J, Dotse E, Asare GA, Ankrah NA. Urinary aflatoxin M1 exposure in Ghanaian children weaned on locally prepared nutritional food. Afr J Sci Res 2015; 4: 28-32.

6. Ismail A, Riaz M, Levin RE, Akhtar S, Gong YY, Hameed A. Seasonal prevalence level of aflatoxin M 1 and its estimated daily intake in Pakistan. Food Control 2016; 60: 461-5. doi: 10.1016/j.foodcont.2015.08.025.

7. Alshannaq A, Yu JH. Occurrence, toxicity, and analysis of major mycotoxins in food. Int J Environ Res Public Health 2017; 14(6): 632. doi: 10.3390/ijerph14060632.

8. Mason S, Arjmandtalab S, Hajimohammadi B, Khosravi Arsanjani A, Karami S, Sayadi M, et al. Aflatoxin M1 Contamination in Industrial and Traditional Yogurts Produced in Iran. J Food Qual Hazards Control 2015; 2(1): 11-4.

9. Olufunmilayo GO, Oyefolu AB. Natural occurrence of aflatoxin residues in fresh and sun-dried meat in Nigeria. Pan Afr Med J 2010; 7: 14.

10. Mohammadi M, Mohebbi G, Hajeb P, Akbarzadeh S, Shojaee I. Aflatoxins in rice imported to Bushehr, a southern port of Iran. American-Eurasian J Toxicol Sci 2012; 4(1): 31-5.

11. Jia R, Ma Q, Fan Y, Ji C, Zhang J, Liu T, et al. The toxic effects of combined aflatoxins and zearalenone in naturally contaminated diets on laying performance, egg quality and mycotoxins residues in eggs of layers and the protective effect of Bacillus subtilis biodegradation product. Food Chem Toxicol 2016; 90: 142-50. doi: 10.1016/j. fct.2016.02.010.

12. Sadeghi N, Oveisi MR, Jannat B, Hajimahmoodi M, Bonyani $\mathrm{H}$, Jannat F. Incidence of aflatoxin M1 in human breast milk in Tehran, Iran. Food Control 2009; 20(1): 75-8. doi: 10.1016/j.foodcont.2008.02.005.

13. Wangia RN, Tang L, Wang JS. Occupational exposure to aflatoxins and health outcomes: a review. J Environ Sci Health C Environ Carcinog Ecotoxicol Rev 2019; 37(4): 215-34. doi: 10.1080/10590501.2019.16648.

14. Shuaib FM, Ehiri J, Abdullahi A, Williams JH, Jolly PE. Reproductive health effects of aflatoxins: a review of the literature. Reorod Toxicol 2010; 29(3): 262-70. doi: 10.1016/j.reprotox.2009.12.005.

15. Agag BI. Mycotoxins in foods and feeds: 1-aflatoxins. Ass Univ Bull Environ Res 2004; 7(1): 173-205.

16. Lawley R, Curtis L, Davis J. The Food Safety Hazard Guidebook. 2nd ed. UK: Royal Society of Chemistry; 2012.

17. Smith LE, Stoltzfus RJ, Prendergast A. Food chain mycotoxin exposure, gut health, and impaired growth: a conceptual framework. Adv Nutr 2012; 3(4): 526-31. doi: 10.3945/an.112.002188.

18. Hussein HS, Brasel JM. Toxicity, metabolism, and impact of mycotoxins on humans and animals. Toxicology 2001; 167(2): 101-34. doi: 10.1016/s0300-483x(01)00471-1.

19. Wu L, Ding X, Li P, Du X, Zhou H, Bai YZ, et al. Aflatoxin contamination of peanuts at harvest in China from 2010 to 2013 and its relationship with climatic conditions. Food Control 2016; 60: 117-23. doi: 10.1016/j. foodcont.2015.06.029. 
20. ISIRI. (Institute of Standard and Industrial Research of I.R. Iran). food \& feed - maycotoxin - maximum tolerated level.5925 . 1st/edition. . 2002.

21. Sabran MR, Jamaluddin R, Mutalib MS. Screening of aflatoxin M 1, a metabolite of aflatoxin B 1 in human urine samples in Malaysia: a preliminary study. Food Control 2012; 28(1): 55-8. doi: 10.1016/j.foodcont.2012.04.048.

22. de Cássia Romero A, Ferreira TR, dos Santos Dias CT, Calori-Domingues MA, da Gloria EM. Occurrence of AFM 1 in urine samples of a Brazilian population and association with food consumption. Food Control 2010; 21(4): 554-8. doi: 10.1016/j.foodcont.2009.08.004.

23. Lei Y, Fang L, Akash MS, Rehman K, Liu Z, Shi W, et al. Estimation of urinary concentration of aflatoxin M1 in Chinese pregnant women. J Food Sci 2013; 78(11): T18358. doi: 10.1111/1750-3841.12259.

24. Ezekiel CN, Oyeyemi OT, Oyedele OA, Ayeni KI, Oyeyemi IT, Nabofa W, et al. Urinary aflatoxin exposure monitoring in rural and semi-urban populations in Ogun state, Nigeria. Food Addit Contam Part A Chem Anal Control Expo Risk Assess 2018; 35(8): 1565-72. doi: 10.1080/19440049.2018.1475752.

25. Ali N, Blaszkewicz M, Hossain K, Degen GH. Determination of aflatoxin $\mathrm{M} 1$ in urine samples indicates frequent dietary exposure to aflatoxin $\mathrm{B} 1$ in the Bangladeshi population. Int J Hyg Environ Health 2017; 220(2 Pt A): 271-81. doi: 10.1016/j.ijheh.2016.11.002.

26. Mason S, Hajimohammadi B, Ehrampoush MH, Khabiri F, Soltani M. A survey on relationship between diet and urinary excretion of aflatoxin M1: a screening pilot study on Iranian population. J Food Qual Hazards Control 2015; 2(2): 66-70.

27. Shuaib FM, Jolly PE, Ehiri JE, Yatich N, Jiang Y, Funkhouser E, et al. Association between birth outcomes and aflatoxin B1 biomarker blood levels in pregnant women in Kumasi, Ghana. Trop Med Int Health 2010; 15(2): 160-7. doi:10.1111/j.1365-3156.2009.02435.x.

28. Bbosa GS, Lubega A, Kyegombe DB, Kitya D, Ogwal-Okeng J, Anokbonggo WW. Review of the biological and health effects of aflatoxins on body organs and body systems: INTECH Open Access Publisher; 2013. doi: 10.5772/51201.

29. Pourvahidi P. Bioclimatic Analysis of Vernacular Iranian Architecture: EMU I-REP (EMU); 2010.

30. Polychronaki N, Wild CP, Mykkänen H, Amra H, AbdelWahhab M, Sylla A, et al. Urinary biomarkers of aflatoxin exposure in young children from Egypt and Guinea. Food Chem Toxicol 2008; 46(2): 519-26. doi: 10.1016/j. fct.2007.08.034.

31. Jager AV, Tonin FG, Baptista GZ, Souto PC, Oliveira CA. Assessment of aflatoxin exposure using serum and urinary biomarkers in São Paulo, Brazil: A pilot study. Int J Hyg Environ Health 2016; 219(3): 294-300. doi: 10.1016/j. ijheh.2015.12.003.

32. Ali N, Hossain K, Blaszkewicz M, Rahman M, Mohanto NC, Alim A, et al. Occurrence of aflatoxin M1 in urines from rural and urban adult cohorts in Bangladesh. Arch Toxicol 2015; 90(7): 1749-55. doi: 10.1007/s00204-0151601-y.

33. Schwartzbord JR, Leroy JL, Severe L, Brown DL. Urinary aflatoxin M1 in Port-au-Prince and a rural community in north-east Haiti. Food Addit Contam Part A Chem Anal Control Expo Risk Assess 2016; 33(6): 1036-42. doi: 10.1080/19440049.2016.1185899.

34. Wogan GN, Kensler TW, Groopman JD. Present and future directions of translational research on aflatoxin and hepatocellular carcinoma. A review. Food Addit Contam Part A Chem Anal Control Expo Risk Assess 2012; 29(2): 249-57. doi: 10.1080/19440049.2011.563370.

35. Polychronaki N, C Turner P, Mykkänen H, Gong Y, Amra $\mathrm{H}$, Abdel-Wahhab $\mathrm{M}$, et al. Determinants of aflatoxin M1 in breast milk in a selected group of Egyptian mothers. Food Addit Contam 2006; 23(7): 700-8. doi: $10.1080 / 02652030600627222$.

36. Jiang R, Jacobs DR Jr, Mayer-Davis E, Szklo M, Herrington D, Jenny NS, et al. Nut and seed consumption and inflammatory markers in the multi-ethnic study of atherosclerosis. Am J Epidemiol 2006; 163(3): 222-31. doi: 10.1093/aje/kwj033.

37. Crozier SR, Robinson SM, Godfrey KM, Cooper C, Inskip HM. Women's dietary patterns change little from before to during pregnancy. J Nutr 2009; 139(10): 1956-63. doi: 10.3945/jn.109.109579.

38. 38 Maslova E, Granström C, Hansen S, Petersen SB, Strøm $\mathrm{M}$, Willett WC, et al. Peanut and tree nut consumption during pregnancy and allergic disease in children-should mothers decrease their intake? Longitudinal evidence from the Danish National Birth Cohort. J Allergy Clin Immunol 2012; 130(3): 724-32- doi: 10.1016/j.jaci.2012.05.014.

39. Ostadrahimi A, Ashrafnejad F, Kazemi A, Sargheini N, Mahdavi R, Farshchian M, et al. Aflatoxin in raw and salt-roasted nuts (pistachios, peanuts and walnuts) sold in markets of tabriz, iran. Jundishapur J Microbiol 2014; 7(1): e8674. doi: 10.5812/jjm.8674.

40. Castells M, Marín S, Sanchis V, Ramos AJ. Reduction of Aflatoxins by Extrusion-Cooking of Rice Meal. J Food Sci 2006; 71(7): C369-77. doi:10.1111/j.17503841.2006.00122.x.

41. Yazdanpanah H, Zarghi A, Shafaati A, Foroutan SM, Aboul-Fathi F, Khoddam A, et al. Analysis of aflatoxin B1 in Iranian foods using HPLC and a monolithic column and estimation of its dietary intake. Iran J Pharm Res 2013; 12(Suppl): 83-9. doi: 10.1111/j.1750-3841.2006.00122.x.

42. Iqbal SZ, Asi MR, Ariño A, Akram N, Zuber M. Aflatoxin contamination in different fractions of rice from Pakistan and estimation of dietary intakes. Mycotoxin Res 2012; 28(3): 175-80. doi: 10.1007/s12550-012-0131-1.

43. Rahmani A, Soleimany F, Hosseini H, Nateghi L. Survey on the occurrence of aflatoxins in rice from different provinces of Iran. Food Addit Contam Part B Surveill 2011; 4(3): 18590- doi: 10.1080/19393210.2011.599865.

44. Ferri F, Brera C, De Santis B, Collini G, Crespi E, Debegnach F, et al. Association between Urinary Levels of Aflatoxin and Consumption of Food Linked to Maize or Cow Milk or Dairy Products. Int J Environ Res Public Health 2020; 17(7): 2510. doi: 10.3390/ijerph17072510.

45. Ferri F, Brera C, De Santis B, Collini G, Crespi E, Debegnach $\mathrm{F}$, et al. Association between urinary levels of aflatoxin and consumption of food linked to maize or cow milk or dairy products. Int J Environ Res Public Health 2020;17(7):2510. doi: 10.3390/ijerph17072510. 
46. Asadi M, Beheshti HR, Feizy J. A survey of aflatoxins in sesame in Iran. Mycotoxin Res 2011; 27(4): 259-63. doi:10.1007/s12550-011-0102-y.

47. Larsson S, Wolk A. Overweight, obesity and risk of liver cancer: a meta-analysis of cohort studies. Br J Cancer 2007; 97(7): 1005-8. doi: 10.1038/sj.bjc.6603932.

48. Vucenik I, Stains JP. Obesity and cancer risk: evidence, mechanisms, and recommendations. Ann NY Acad Sci2012; 1271(1): 37-43. doi:10.1111/j.1749-6632.2012.06750.x.

49. Wang JS, Huang T, Su J, Liang F, Wei Z, Liang Y, et al. Hepatocellular carcinoma and aflatoxin exposure in Zhuqing village, Fusui county, People's Republic of China. Cancer Epidemiol Biomark Prev 2001; 10(2): 143-6.

50. Barrett JR. Liver cancer and aflatoxin: new information from the Kenyan. Environ Health Perspect 2005; 113(12): 837-8.

51. Turner PC, Collinson AC, Cheung YB, Gong Y, Hall AJ,
Prentice AM, et al. Aflatoxin exposure in utero causes growth faltering in Gambian infants. Int J Epidemiol 2007; 36(5): 1119-25. doi: 10.1093/ije/dym122.

52. Denli M, Celik K, Okan F. Effects of vitamin a supplementary in the feed to reduce toxic effects of aflatoxin B1 on Japanese quails (Coturnix coturnix Japonica). Int J Poult Sci 2003; 2(2): 174-7. doi: 10.3923/ijps.2003.174.177.

53. El-Nezami HS, Polychronaki NN, Ma J, Zhu H, Ling W, Salminen EK, et al. Probiotic supplementation reduces a biomarker for increased risk of liver cancer in young men from Southern China. Am J Clin Nutr 2006; 83(5): 1199203. doi: 10.1093/ajcn/83.5.1199.

54. Khlangwiset P, Wu F. Costs and efficacy of public health interventions to reduce aflatoxin-induced human disease. Food Addit Contam Part A Chem Anal Control Expo Risk Assess 2010; 27(7): 998-1014. doi: $10.1080 / 19440041003677475$. 